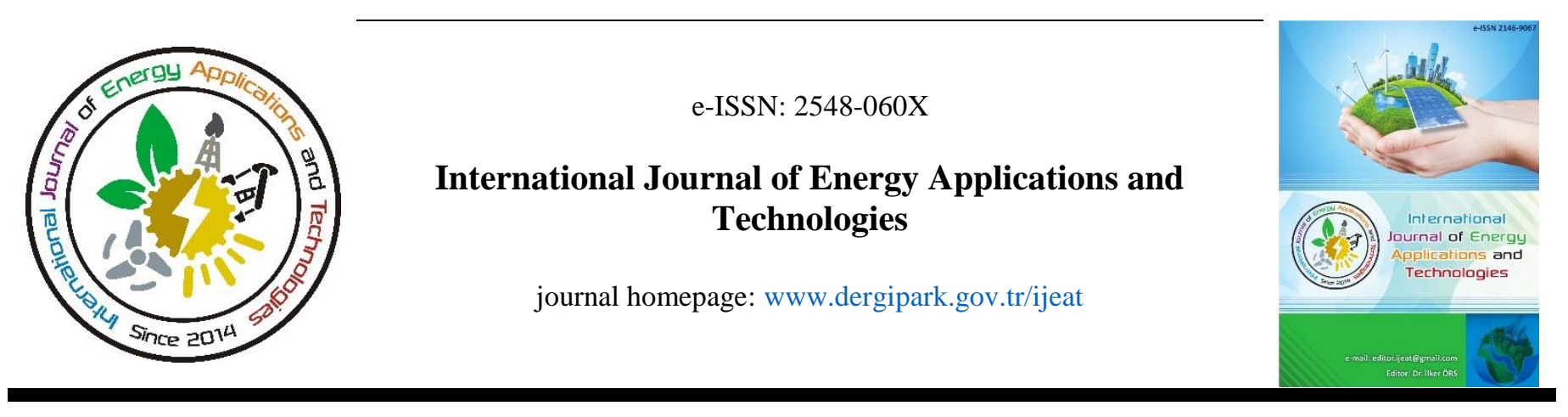

Original Research Article

\title{
Application of auto-regressive time series model to marginal oil field production in Nigeria
}

\author{
Samuel Ayodeji Omotehinse ${ }^{1 *}$, Henry E. Idudje ${ }^{2}$ \\ ${ }^{I}$ Research Scholar, Department of Production/Industrial Engineering, University of Benin, P.M.B 1154, Benin City, Edo State, Nigeria \\ ${ }^{2}$ Department of Petroleum Engineering, Federal University of Petroleum Resources, Effurun, Delta State. Nigeria
}

\author{
ARTICLE INFO \\ * Corresponding author \\ drsamayodeji@gmail.com \\ Received July 2, 2020 \\ Accepted February 9, 2021 \\ Published by Editorial Board \\ Members of IJEAT \\ (C) This article is distributed by \\ Turk Journal Park System under \\ the CC 4.0 terms and conditions \\ doi: 10.31593/ijeat.762290
}

\begin{abstract}
Some concern has been expressed over the continuous low production from Marginal oil field. This production problem has been ascribed to multitude of hindrances occasioned by the nature of earth formation in the zone. Attempts to ascertain the character or complexion of such problems have often eluded researchers and operators of the field. This study adopts the use of auto-regressive time series model to find out the root cause or the mechanism that generate high output or low output in marginal field. The correlogram that captures the memory of the mechanism that generated the output process was established. And by judiciously picking and choosing the right lags from the correlogram, model that replicates the production process mechanism was also established. The result obtained shows that there is a close tracking of the forecast with the actual. Evidently, the Mean absolute percentage error (MAPE) obtained is $5.07 \%$ showing that the errors in forecast are marginal suggesting that the forecast is robust if not sure-fire.
\end{abstract}

Keywords: Auto-regression; Forecast; Marginal field; Oilfield; Time series

\section{Introduction}

Marginal field often have low crude oil production. This production problem has been ascribed to multitude of hindrances occasioned by the nature of earth formation in the zone. Attempts to ascertain the character or complexion of such problems have often eluded researchers and operators of the field. The country in which the marginal field is located tends to show more concern about factors that hinder continuous production from these marginal fields. For economic reasons, they tend to research the mechanics of the cause of low yield from marginal fields. It is therefore important that a research of this nature be conducted. Accordingly, many researches have been conducted to find out why yields in marginal fields are marginal. The proposed solution to tracing the mechanics of low production centers on the application of auto-regressive model. It uses the correlation between adjacent observations in a time-series to find out the root cause or the mechanism that generate high output or low output as the case may be. It starts by having an outlay of possible lags giving the spread or length of the time series data and by using a special tool called autocorrelation function $r_{k}$, given by;

$$
r_{k}=\frac{\sum_{t=1}^{T-K}\left(y_{t}-\bar{y}\right)\left(y_{t+k}-\bar{y}\right)}{\left(y_{t}-\bar{y}\right)^{2}}
$$

With the auto-correlation function $r_{k}$ correlogram that captures the memory of the mechanism that generated the output process can be established. This correlogram can be referred to as a statistical black box, comparable to the black box that records flight's incidents. And by judiciously picking and choosing the right lags from the correlogram, model that would replicate the production process mechanism can also be established. If the choice of these lags is done with sagacity, a robust or sure-fire model that acts 
like the original production process mechanism which generated the data will be re-generated. This model even acts better than artificial intelligence.

Research work on marginal field exploration dates back to early 1950s when Shell Petroleum Development Company (SPDC) started oil exploration in the Niger Delta of Nigeria and continues up to 1970 s. Some of the researchers reported that there were many wild-cats well that were explored. Some of them yielded marginal well output and therefore classified as marginal fields. Notable among such papers are: [1-4]. Oil exploration also continue when majority of the explorations snowballed which contributed to oil boom of that era. See for example, [5-8]. Similar studies include: [9-11].

Contemporary researches on marginal field started gaining importance when the International Oil Companies (IOCs) started showing disinterest in this fields and Nigerian investors and venture capitalist that didn't have the stock of capitals the IOC yields showed renewed interest in the field. One outstanding fact about their discovery is that the marginal fields are replete with high risk and therefore they try to study the risk return profile to evaluate when it is desirable to invest. Research studies such as [12-15] evaluated some of the risks. Others include: [16-21]. A number of studies have been conducted also on the technological [22-25] and economic factors [26-30], affecting oil and gas field development across the globe and Nigeria in specific. The overview of the emergence of marginal oil fields in Nigeria and their contribution to the country's oil production was considered by [31] while [32] examined the controversy surrounding the development of marginal oilfields in Nigeria as well as [33] who assessed the critical success factors of marginal oil field development in Niger Delta region of Nigeria. The foregoing sample review revealed that there is a balance of literature on marginal oil field production but a dearth on the use of auto-regressive model to forecast yield from the representative well of the marginal fields. The aim of this study therefore is to use autoregressive model to describe the mechanisms that tend to generate yields in marginal field production. Such knowledge could characterize the nature and complexion of production in marginal field.

\section{Methodology}

This is an applied research involving the collection of 68-day daily production data from a marginal oil field in the Niger Delta. In other to replicate or describe the mechanism that gave rise to this production, the time-series obtain was analyze with auto-regressive model described in equation 1. Autocorrelation functions $r_{k}$ were computed using lags developed from the time-series. Following this, a correlogram, which as earlier said, is like a black box detailing the incidents of the production process was obtained. Influential lags were accordingly used to develop auto-regressive model and the set of subsequent normal equations were solved by MATLAB software R2013a. The auto-regressive model that emerged was very simple in form and structure. A set of errors arising from the difference between actual and predicted were used as a check for model adequacy. The set of normal equations developed for this study is given below:

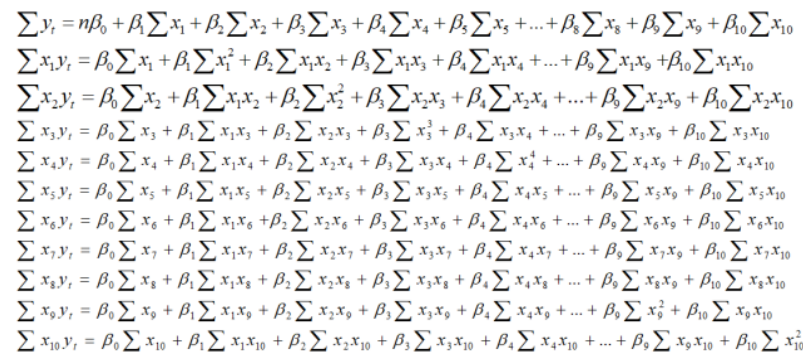

Substituting the respective values of the parameters in equation (2) we have equation 3 :

$188771=68 \beta_{0}+186017 \beta_{1}+183252 \beta_{2}+180487 \beta_{3}+\ldots+65765 \beta_{10}$ $516768118=186017 \beta_{0}+517374151 \beta_{1}+509153308 \beta_{2}+\ldots+177816120 \beta_{10}$ $508465718=183252 \beta_{0}+509153308 \beta_{1}+509728926 \beta_{2}+\ldots+177616939 \beta_{10}$

$$
178068121=65765 \beta_{0}+177816120 \beta_{1}+177616939 \beta_{2}+\ldots+188203957 \beta_{10}
$$

This set of normal equations in beta $(\beta)$ had its coefficients extracted to form a coefficient or adjoint matrix that was solved with Matlab software R2013a. Table 1 depicts the correlation coefficients obtained from the Matlab solution.

Table 1. Correlation coefficients

\begin{tabular}{cc}
\hline Correlation Coefficient & Correlation Coefficient Value \\
\hline$\beta_{0}$ & 2792.6 \\
$\beta_{1}$ & 0.1000 \\
$\beta_{2}$ & -0.0000 \\
$\beta_{3}$ & 0.0000 \\
$\beta_{4}$ & -0.1000 \\
$\beta_{5}$ & 0.1000 \\
$\beta_{6}$ & -0.0000 \\
$\beta_{7}$ & -0.0000 \\
$\beta_{8}$ & -0.1000 \\
$\beta_{9}$ & 0.0000 \\
$\beta_{10}$ & 0.0000 \\
\hline
\end{tabular}

The resulting autoregressive model is given by

$\hat{y}_{t}=\beta_{0}+\beta_{1} y_{t-1}+\beta_{2} y_{t-2}+\beta_{3} y_{t-3}+\beta_{4} y_{t-4}+\beta_{5} y_{t-5}+\beta_{6} y_{t-6}+\beta_{7} y_{t-9}+\beta_{8} y_{t-35}+\beta_{9} y_{t-36}+\beta_{10} y_{t-45}$

Where 1, 2, 3, 4, 5, 6, 9, 35, 36, 45 are the most influential lags selected from the correlogram as outlined in Figure 1. Substituting the respective correlation coefficients 
$\beta_{0}, \beta_{1}, \beta_{2}, \beta_{4}, \beta_{5}+\ldots+\beta_{9}, \beta_{10}$ obtained into equation (4) yields model prediction given as

$\hat{y}_{t}=2792.6+0.1 y_{t-1}-0.1 y_{t-4}+0.1 y_{t-5}-0.1 y_{t-35}$

Where $\beta_{2}, \beta_{3}, \beta_{6}, \beta_{7}, \beta_{9}, \beta_{10}=0$

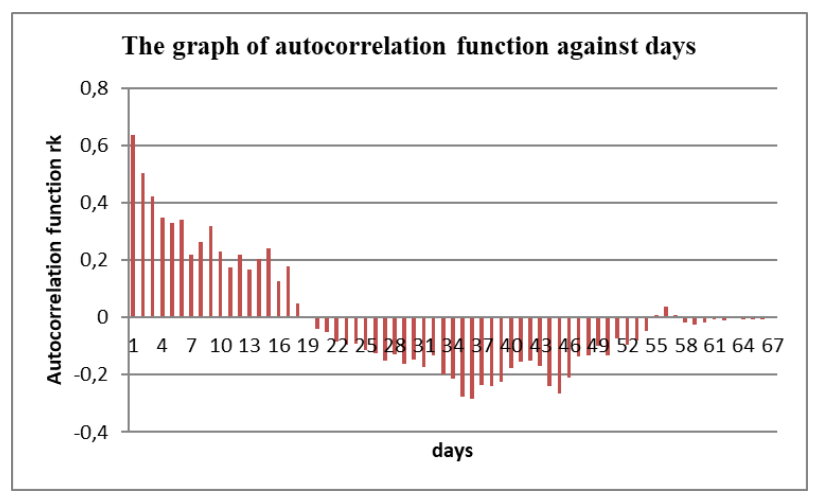

\section{Results and Discussion}

Table 2 shows the forecast along with the actual data and the associated errors.

If we eyeball the forecast against the actual as well as the residuals, it will be seen that there is a close tracking of the forecast with the actual as shown in Figure 2.

Figure 2 depicts the chart of the daily oil well production data forecast tracking the actual data.

Evidently, the errors are marginal suggesting that the forecast is robust if not sure-fire. As expected all forecast are always imprecise. The mean absolute percentage error (MAPE) is $5.07 \%$ showing that the error in forecast is marginal. Again out of sample forecast was conducted for 5days; the associated errors are shown below:

Fig. 1. Graph of auto-correlation function against days

Table 2. In-sample forecast and associated errors

\begin{tabular}{cccccccccccc}
\hline $\mathbf{t}$ & $\boldsymbol{y}_{\boldsymbol{t}}$ & $\widehat{\boldsymbol{y}}_{\boldsymbol{t}}$ & $\boldsymbol{e}_{\boldsymbol{t}}$ & $\mathbf{t}$ & $\boldsymbol{y}_{\boldsymbol{t}}$ & $\widehat{\boldsymbol{y}}_{\boldsymbol{t}}$ & $\boldsymbol{e}_{\boldsymbol{t}}$ & $\mathbf{t}$ & $\boldsymbol{y}_{\boldsymbol{t}}$ & $\widehat{\boldsymbol{y}}_{\boldsymbol{t}}$ & $\boldsymbol{e}_{\boldsymbol{t}}$ \\
\hline $\mathbf{1}$ & 2851 & 2792.6 & 58.4 & $\mathbf{2 2}$ & 2756 & 3094.9 & -338.9 & $\mathbf{4 3}$ & 2765 & 2774.6 & -9.6 \\
$\mathbf{2}$ & 2958 & 3077.7 & -119.7 & $\mathbf{2 3}$ & 2735 & 3060.2 & -325.2 & $\mathbf{4 4}$ & 2667 & 2775.7 & -108.7 \\
$\mathbf{3}$ & 2918 & 3088.4 & -170.4 & $\mathbf{2 4}$ & 2634 & 3069.2 & -435.2 & $\mathbf{4 5}$ & 2656 & 2756.5 & -100.5 \\
$\mathbf{4}$ & 2897 & 3084.4 & -187.4 & $\mathbf{2 5}$ & 2963 & 3054 & -91 & $\mathbf{4 6}$ & 2676 & 2766.2 & -90.2 \\
$\mathbf{5}$ & 2765 & 2797.2 & -32.2 & $\mathbf{2 6}$ & 2867 & 3096.7 & -229.7 & $\mathbf{4 7}$ & 2656 & 2779.9 & -123.9 \\
$\mathbf{6}$ & 2975 & 3058.4 & -83.4 & $\mathbf{2 7}$ & 2846 & 3081.4 & -235.4 & $\mathbf{4 8}$ & 2598 & 2789.5 & -191.5 \\
$\mathbf{7}$ & 2873 & 3094.1 & -221.1 & $\mathbf{2 8}$ & 2954 & 3087.3 & -133.3 & $\mathbf{4 9}$ & 2676 & 2774.5 & -98.5 \\
$\mathbf{8}$ & 2943 & 3082 & -139 & $\mathbf{2 9}$ & 2903 & 3055.1 & -152.1 & $\mathbf{5 0}$ & 2687 & 2778.8 & -91.8 \\
$\mathbf{9}$ & 2856 & 3100.1 & -244.1 & $\mathbf{3 0}$ & 2845 & 3092.5 & -247.5 & $\mathbf{5 1}$ & 2675 & 2763.8 & -88.8 \\
$\mathbf{1 0}$ & 2934 & 3057.2 & -123.2 & $\mathbf{3 1}$ & 2945 & 3079.2 & -134.2 & $\mathbf{5 2}$ & 2553 & 2770.5 & -217.5 \\
$\mathbf{1 1}$ & 2985 & 3096.2 & -111.2 & $\mathbf{3 2}$ & 2770 & 3076.3 & -306.3 & $\mathbf{5 3}$ & 2654 & 2763.6 & -109.6 \\
$\mathbf{1 2}$ & 2743 & 3084.1 & -341.1 & $\mathbf{3 3}$ & 2705 & 3074.7 & -369.7 & $\mathbf{5 4}$ & 2564 & 2772.4 & -208.4 \\
$\mathbf{1 3}$ & 2785 & 3075.6 & -290.6 & $\mathbf{3 4}$ & 2765 & 3068.9 & -303.9 & $\mathbf{5 5}$ & 2564 & 2768.8 & -204.8 \\
$\mathbf{1 4}$ & 2790 & 3063.3 & -273.3 & $\mathbf{3 5}$ & 2667 & 3059.1 & -392.1 & $\mathbf{5 6}$ & 2565 & 2777.8 & -212.8 \\
$\mathbf{1 5}$ & 2794 & 3066.5 & -272.5 & $\mathbf{3 6}$ & 2656 & 2791.7 & -135.7 & $\mathbf{5 7}$ & 2867 & 2763.4 & 103.6 \\
$\mathbf{1 6}$ & 2995 & 3096.2 & -101.2 & $\mathbf{3 7}$ & 2676 & 2768.9 & -92.9 & $\mathbf{5 8}$ & 2876 & 2814.8 & 61.2 \\
$\mathbf{1 7}$ & 2954 & 3087.9 & -133.9 & $\mathbf{3 8}$ & 2656 & 2762.4 & -106.4 & $\mathbf{5 9}$ & 2887 & 2816.8 & 70.2 \\
$\mathbf{1 8}$ & 2765 & 3087.5 & -322.5 & $\mathbf{3 9}$ & 2598 & 2778.3 & -180.3 & $\mathbf{6 0}$ & 2765 & 2784.9 & -19.9 \\
$\mathbf{1 9}$ & 2845 & 3068.7 & -223.7 & $\mathbf{4 0}$ & 2676 & 2777 & -101 & $\mathbf{6 1}$ & 2677 & 2752.2 & -75.2 \\
$\mathbf{2 0}$ & 2814 & 3057 & -243 & $\mathbf{4 1}$ & 2770 & 2760.7 & 9.3 & $\mathbf{6 2}$ & 2776 & 2774.8 & 1.2 \\
$\mathbf{2 1}$ & 2834 & 3078.1 & -244.1 & $\mathbf{4 2}$ & 2705 & 2784.3 & -79.3 & $\mathbf{6 3}$ & 2779 & 2773.7 & 5.3 \\
\hline
\end{tabular}

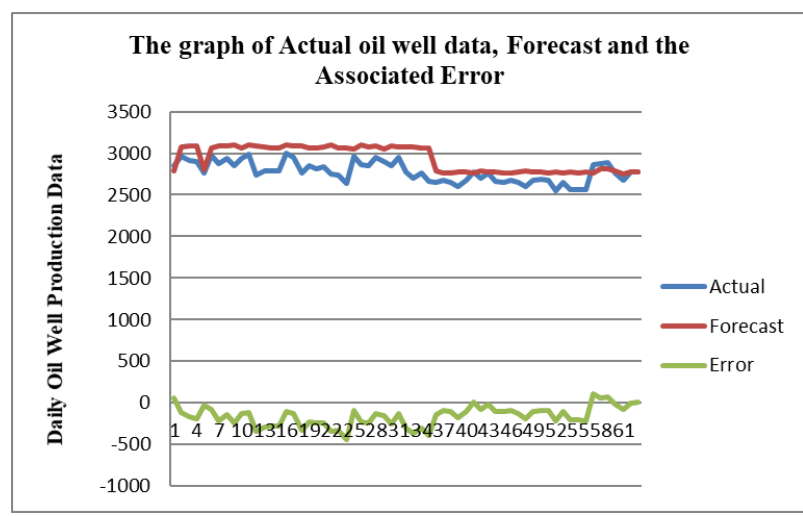

Fig. 2. Graph of Actual oil well production data, Forecast and the associated Error
Table 3. Out of sample forecast and associated errors

\begin{tabular}{cccc}
\hline $\mathbf{t}$ & $\boldsymbol{y}_{\boldsymbol{t}}$ & $\widehat{\boldsymbol{y}}_{\boldsymbol{t}}$ & $\boldsymbol{e}_{\boldsymbol{t}}$ \\
\hline $\mathbf{6 4}$ & 2758 & 2792.4 & -34.4 \\
$\mathbf{6 5}$ & 2780 & 2796.14 & -16.14 \\
$\mathbf{6 6}$ & 2765 & 2766.2 & -1.2 \\
$\mathbf{6 7}$ & 2765 & 2791.8 & -26.8 \\
$\mathbf{6 8}$ & 2754 & 2800.7 & -46.7 \\
\hline
\end{tabular}

\section{Conclusion}

The auto-regressive model developed in this study has been able to track the 68-day daily production data obtained from marginal oil field in the Niger Delta region of Nigeria. The model has successfully replicated and describes the mechanism that gave rise to the yields in marginal field. 
Using auto-regression analysis, the study revealed the nature of marginal oil field daily production data considered in this study. Such knowledge could characterize the nature and complexion of production in marginal field. The problems of marginal field development are not confined to just one constraint, although the mixture of constraints that marginal field operators face varies from one country to another. Some of the major factors hindering marginal field development in the country are low level of support infrastructure, funding constraints, high operational and capital expenditure, insufficient policy, and institutional framework.

\section{$\underline{\text { ORCID }}$}
S. A. Omotehinse
0000-0002-5036-0800
H. E. Idudje
0000-0001-7818-8179

\section{References}

[1] Milton, A. 1980. A Progressive Approach to Marginal Field Development in S.E. Asia, paper SPE 8851 presented at the 1980 SPE session of Offshore South East Asia Conference, Feb.26 - 29.

[2] Department of Petroleum Resources, 1996. Guidelines for the Farm-out and Operations of Marginal Fields.

[3] Frynas, J. G. 1999. Oil in Nigeria: Conflict and litigation between oil companies and village communities. Münster: Lit Verlag.

[4] Aret, A. G. 2001. Marginal Field Developments. SPE Nigeria Council Sponsored Workshop NICON Hilton Hotel, Abuja, Nigeria, 16 March.

[5] Boyne, K., Horn, M., Bertrane, D., Fournie, F., Cooper, T., Quinn, P., Coudeville, F., Buchan, D., Allan, K. 2003. Otter- A Challenging Marginal oil Field Development. Paper SPE 83975 presented at offshore Europe 2003 held in Aberdeen, UK, 2-5, September 2003.

[6] Ayodele, O.R. and Frimpong, S. 2003. Economics of Nigerian Marginal Oil Fields. Paper presented at the SPE Hydrocarbon Economics and Evaluation

Symposium held in Dallas, Texas, U.S.A., 5-8 April 2003.

[7] Kue, Y.N. and Orodu, O.D. 2006. Economic Analysis of Innovative Approaches to Marginal Field Development. Paper presented at the 30th Annual SPE international Technical Conference and Exhibition in Abuja, Nigeria, July31-August 2.

[8] Sumeet, G. and Tushar, G. 2012. Enhancing Marginal Field Development Economics: Leasing Operated Production Facilities Approach, Research Centre of social Sciences Journal of Global Economy, Vol. 8, pg 63-71.

[9] Adetoba, L. A. 2012. The Nigerian Marginal Field Initiative: Recent Developments. SPE 163040 paper presented at the Nigeria Annual International Conference and Exhibition held in Abuja, Nigeria, 6-8 August 2012.

[10] Choudhury, N.N. and Verma, S.K. 2016. Discovery of Development of Guda- A Case Study of a Marginal Field. Presented at the 12th Biennial International Oil and Gas Conference and Exhibition, India, 5-7 December.

[11] Oyakhire, B. and Omeke, J. 2017. Best Practice for Marginal Oil Field Development and Production Sustainability beyond First Oil Production. - Niger Delta Case. A paper presented at the Nigeria Annual International Conference and Exhibition held in Lagos, Nigeria, 31 July-2 August.

[12] Schuyler, J.R. 2001. Risk and decision analysis in projects. 2nd ed. Pennsylvania: Project Management Institute.

[13] Flyvbjerg, B., Holm, M.K.S., and Buhl, S.L. 2005. How inaccurate are demand forecasts in public works projects? Journal of the American Planning Association, 78(2), pp.131-146.

[14] Alaneme, C.E. and Igboanugo, A.C. 2012. Application of Decision Theory in Assessing Marginal Oilfield Risks: Niger Delta Hub Example. Journal of Emerging Trends in Engineering and Applied Sciences, 3(4): 594600.

[15] Graham, G.M. and Collins, I.R. 2004. Assessing Scale Risks and Uncertainties for Subsea Marginal Field Developments. A paper presented at the 6th international Symposium on Oilfield Scale held in Aberdeen, UK, 26-27 May.

[16] Ward, S.C. and Chapman, C.B. 1991. Extending the use of risk analysis in project management. International Journal of Project Management, 9(2), pp. 117-123.

[17] Harbaugh, J., Davis, J., and Wendebourg, J. 1996. Computing risk for oil prospects: Principles and programs. Elsevier Science, 13(7), pp.852. 
[18] McCray, G.E., Purvis, R.L., and McCray, C.G. 2002. Project Management under Uncertainties: The Impact of Heuristics and Biases. Project Management Journal, 33(1), pp.49-57.

[19] Inyang, E. and Oyinlola, S. 2006. Security Matrix in the Niger Delta Operations. Paper presented at the SPE international Conference on Health, Safety, and Environment in Oil and Gas Exploration and Production held in Abu Dhabi, U.A.E, 2-4 April 2006.

[20] Rose, P. 2012. Risk Analysis and Management of Petroleum Exploration Ventures. AAPG Methods in Exploration Series, No. 12. American Association of Petroleum Geologists, Tulsa USA.

[21] Andersen, S. and Mostue, B.A. 2011. Risk analysis and risk management approaches applied to the petroleum industry and their applicability to IO concepts. Safety Science.50 (10), pp. 2010-2019.

[22] Kaiser, M. 2010. Marginal production in the gulf of Mexico - I. Historical statistics \& model framework. Applied Energy, 87(8), 2535-2550.

[23] Offia, U. 2011. Development and management of marginal oil field in the Niger delta basin: Opportunities and challenges. Petroleum Technology Development Journal: An International Journal, 1(1), 1-10.

[24] Devold, H. 2013. Oil and Gas Production Handbook: An Introduction to Oil and Gas Production, Transport, Refining and Petrochemical Industry. Oslo, Norway: ABB Oil and Gas Edition.

[25] Akinwale, Y.O. and Akinbami, J.K. 2016. Economic Evaluation of Nigerian Marginal Oil and Gas Field using Financial Simulation Analysis. International Journal of Energy Economics and Policy, 6(3), 563574.

[26] Ayodele, O.R. and Frimpong, S. 2003. Economics of Nigerian Marginal Oil Fields. Paper presented at the SPE Hydrocarbon Economics and Evaluation Symposium held in Dallas, Texas, U.S.A., 5-8 April 2003.

[27] Iledare, O. 2004. Analyzing the Impact of Petroleum Fiscal Arrangements and Contract Terms on Petroleum E\&P Economics and Host Government Take. Society of Petroleum Engineers (SPE) 88969: Nigeria Annual International Conference and Exhibition on Petroleum, 2-4 August, Abuja, Nigeria.

[28] Adenikinju, A. and Oderinde, L. 2009, Economics of Offshore Oil Investment Projects and Production Sharing Contracts: A Meta Modeling Analysis. Nigeria: University of Ibadan. Available from: http://www.africametrics.org/documents/conference09 /papers/ Adenikinju_Oderinde.pdf. [Last accessed on 2015 May 02].
[29] Adamu, M., Ajienka, J., Ikiensikimama, S. 2013 Economic analysis on the development of Nigerian offshore marginal fields using probabilistic approach. Advances in Petroleum Exploration and Development, 6(1), 11-21.

[30] Akinwale, Y.O. and Akinbami, J.K. 2016. Economic Evaluation of Nigerian Marginal Oil and Gas Field using Financial Simulation Analysis. International Journal of Energy Economics and Policy, 6(3), 563574.

[31] Eze, C. L., Godwin, A. C., Dominic, E. U. 2017. Overview On the Emergence of Marginal Oil Fields in Nigeria and Their Contribution to The Country's Oil Production. Nigerian Journal of Oil and Gas Technology - Vol 2 No. 1. pp. 229-236.

[32] Atsegbua, L. 2005. Issues in the Development of Marginal Oilfields in Nigeria, Journal of Energy \& Natural Resources Law, 23:3, 323-336.

[33] Humphrey, O., and Dosunmu, A. 2017. The Critical Success Factors for Marginal Oil Field Development in Nigeria. Journal of Business and Management Sciences, 2017, Vol. 5, No. 1, 1-10. 